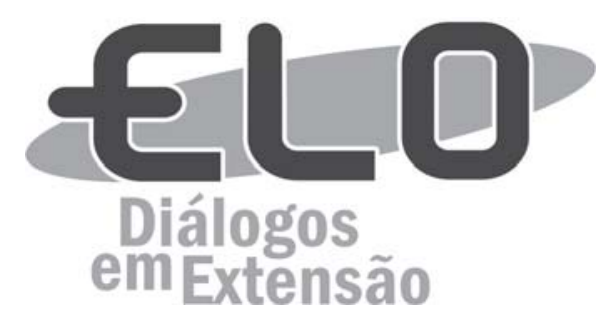

\title{
Bioquímica nas escolas: uma estratégia educacional para o estudo de Ciência no Ensino Médio
}

\author{
Lethícia Ribeiro Henriques ${ }^{1}$, Isaac Filipe Moreira Konig르, Bárbara Karina de Menezes Dias ${ }^{3}$, \\ Flávia Fonseca Bagno ${ }^{4}$, Raquel Cristina Vieira dos Santos ${ }^{5}$, João Paulo Viana Leite ${ }^{6}$
}

\begin{abstract}
Resumo: A formação continuada de professores do Ensino Médio, no que tange as ciências da natureza, tem o desafio de incorporar, no conteúdo programático, as pesquisas e tecnologias inovadoras resultantes das novas descobertas no campo da Bioquímica e da Biologia Molecular. O presente trabalho relata a experiência de um projeto de extensão que objetivou a capacitação de professores de Biologia e de Química para o uso de novos métodos de ensino-aprendizagem visando despertar maior interesse dos estudantes pela Ciência. Resultado de parceria en tre professores e estudantes universitários com educadores de escolas públicas, o presente projeto possibilitou a capacitação de 34 professores oriundos de 17 diferentes escolas para a utilização de um método de ensino-aprendizagem baseado no emprego de modelos didáticos lúdicos e de problematização da realidade quanto ao consumo de tecnologias e produtos biotecnológicos.
\end{abstract}

Palavras-chave: Didática. Ensino. Ensino médio. Ciência. Bioquímica.

Área Temática: Educação.

\section{Biochemistry at school: an educational strategy for the study of Science in high school}

Abstract: Continued education of high school teachers regarding natural sciences has been challenging in terms of incorporating researches and innovative technologies from discoveries in the field of biochemistry and molecular biology in the curriculum. This paper describes the experience of an extension project aimed at training biology and chemistry teachers for the use of new teaching and learning methods to arouse a greater interest of students for science. Resulting from a partnership between professors and undergraduate students with public school teachers, this project enabled the training of 34 teachers from 17 different schools. The teaching-learning method establishes on the use of didactic models as well as the problem-based knowledge of reality regarding the consumption of technology and biotechnology products.

Keywords: Didactics. Education. High school. Science. Biochemistry.

\section{Bioquimica en los colegios: una estrategia educacional para el estudio de ciencias en la educación secundaria}

Resumen: La continua formación de los profesores de educación secundaria con respecto a las ciencias naturales, tiene el desafío de ir incorporando en el contenido programático los resultados de las investigaciones y las tecnologías innovadoras descubiertos en el campo de la bioquímica y la biología molecular. El presente trabajo relata la experiencia de un proyecto de extensión cuyo objetivo es la capacitación de profesores de

\footnotetext{
${ }^{1}$ Universidade Federal de Minas Gerais. Mestranda em Microbiologia. (henriques.lethicia@gmail.com)

${ }^{2}$ Universidade Federal de Viçosa. Estudante de Graduação em Bioquímica.

${ }^{3}$ Universidade Federal de Viçosa. Bacharel em Bioquímica.

${ }^{4}$ Universidade Federal de Viçosa. Mestranda em Microbiologia Agrícola.

${ }^{5}$ Universidade Federal de Viçosa. Professora do Departamento de Bioquímica e Biologia Molecular.

${ }^{6}$ Universidade Federal de Viçosa. Professor do Departamento de Bioquímica e Biologia Molecular.
} 
biología y de química para el uso de nuevos métodos de enseñanza y aprendizaje, buscando despertar un mayor interés de los estudiantes por la ciencia. Como resultado de la asociación entre profesores y estudiantes con docentes de colegios públicos, el presente proyecto posibilitó la capacitación de 34 profesores de 17 diferentes colegios en el uso del método de enseñanza-aprendizaje basado en el empleo de modelos ludo-didácticos y de problematización de la realidad en cuanto al consumo de tecnologías y productos biotecnológicos.

Palabras clave: Didáctica. Educación. Escuela secundaria. Ciencia. Bioquímica.

\section{Introdução}

Ao longo da história, a ciência tem servido de sustentação para as tecnologias inovadoras, sendo a base da civilização moderna. O surgimento dessa ciência está relacionado às raízes da própria espécie humana que é dotada da capacidade e da curiosidade de entender a si mesma e ao mundo (Mlodinow, 2015). Originado do Renascimento cultural, científico e artístico, o movimento Iluminista do Século XVII e XVIII acreditava que a razão e a ciência eram as bases para a compreensão do mundo. Um dos principais precursores do Iluminismo da época, René Descartes (1596-1650), em sua obra 'Discurso do Método' (1637), adotou a dúvida sistemática como meio para encontrar a verdade. Segundo Descartes, deveríamos duvidar de tudo, sendo que esta dúvida acabaria por meio da comprovação científica das coisas ou dos seres.

No entanto, ao passo que a ciência se mostrava como fermento de uma transformação social baseada na técnica, vários autores começam a refletir sobre o impacto dessa ordem científica emergente nos fundamentos da sociedade moderna. Segundo o sociólogo Boaventura Santos (2005):

Promovidos pela rápida conversão da ciência em força produtiva, os critérios científicos de eficiência e eficácia logo se tornaram hegemônicos, ao ponto de colonizarem gradualmente os critérios racionais das outras lógicas emancipatórias.

Diante desse contexto histórico, que caminha em direção a uma sociedade cada vez mais dependente da ciência e da tecnologia, ao passo que, concomitantemente, percebe-se um paradoxal conflito entre a disponibilização e o controle desse conhecimento científico, constituindo-se em uma antiga questão de poder que cria obstáculo para o seu domínio e acesso (Germano, 2011), surge a problematização que buscaremos discutir neste trabalho: como abordar a ciência nas escolas.

É certo que na esteira da mesma curiosidade que motivou o homem na busca de resposta para explicar os fenômenos naturais, hoje os professores percebem uma diminuição do interesse dos alunos pelos porquês dentro da sala de aula se tornando um grande desafio para o ensino de ciência. Este desencanto dos estudantes em relação à ciência escolar tem repercutido no baixo interesse por parte dos mesmos em seguir carreiras científicas (Vázquez; Manassero, 2008).

Gouw e colaboradores (2013), em projeto intitulado "The Relevance of Science Education", envolvendo 2.365 estudantes de todos os estados brasileiros, oriundos de 84 escolas, buscaram ouvir o que os alunos têm a dizer das aulas de Ciências e dos temas científicos. Os autores concluíram que os alunos brasileiros possuem grande interesse pelos temas científicos abordados na escola, sendo os temas de maior interesse aqueles relacionados à biologia humana. Também pode-se verificar que os jovens estudantes brasileiros estão abertos a discussões sobre o tema.

Nos últimos anos, para o processo de ensino-aprendizagem de Ciências, vários professores têm apontado a necessidade de busca de modelos que aumentem a motivação dos alunos, sugerindo a aquisição de conhecimentos científicos a processos cognitivos e afetivos ou também trazendo o tema para mais próximo à vida cotidiana do estudante. Fourez (2003), após revisão crítica sobre os principais problemas enfrentados pelo ensino de Ciência nas escolas na atualidade, faz a seguinte reflexão:

Os alunos teriam a impressão de que se quer obrigá-los a ver o mundo com os olhos de cientistas. Enquanto o que teria sentido para eles seria um ensino de Ciências que ajudasse a compreender o mundo deles. Isto não quer dizer, absolutamente, que gostariam de permanecer em seu pequeno universo; mas, para que tenham sentido para eles os modelos científicos cujo estudo lhes é imposto, estes modelos deveriam permitir-lhes compreender a sua história e o seu mundo. 
Buscando contribuir para a melhoria do processo ensino-aprendizagem no campo da Ciência, sobretudo aquele relacionado a processos bioquímicos, o presente artigo relata um projeto de extensão universitária realizado pela equipe do Programa de Educação Tutorial (PET) do curso de Bacharelado em Bioquímica da Universidade Federal de Viçosa (UFV) em parceria com o Centro de Biotecnologia Molecular Estrutural (CBME), do Instituto de Física de São Carlos da Universidade de São Paulo (USP) e com a Superintendência Regional de Ensino (SRE) do município de Ponte Nova, Minas Gerais (MG).

Nos últimos anos, no campo da bioquímica e da biologia molecular, as pesquisas propiciaram uma rápida evolução do conhecimento e de suas tecnologias associadas, gerando uma lacuna na formação acadêmica de um grande número de professores. Este fato tem dificultado a abordagem de temas relevantes e de interesse do aluno do ensino médio dentro da sala de aula. Neste sentido, de acordo com Bossolan e colaboradores (2005):

\begin{abstract}
... os alunos demandam esse conhecimento por influência de fontes de informação como, por exemplo, a imprensa escrita e falada, onde (sic) esses temas têm ocupado um espaço regular. Assim, percebe-se que os professores têm a necessidade premente de atualização e aperfeiçoamento nesses assuntos. Nesse contexto, o papel da universidade, como geradora, difusora e disseminadora de conhecimento, é o de, através de parcerias com as escolas públicas, diminuir o espaço temporal que existe entre os avanços alcançados nessa área e a sala de aula.
\end{abstract}

Loguercio e colaboradores (2007), relataram que a década de 90 foi marcada pelo desenvolvimento de trabalhos que trouxeram para o cenário da educação um novo ramo do saber: a Educação em Bioquímica. Uma justificativa para essa ascensão tardia da Bioquímica diante das outras ciências pode ser citada:

\begin{abstract}
A Bioquímica usa bastante a abstração e a imaginação para descrever os fenômenos que acontecem em nível molecular, e é difícil representar seus fenômenos somente com o auxílio dos instrumentos mais amplamente usados no cotidiano escolar, o quadro-negro e o retroprojetor. (Machado et al., 2010).
\end{abstract}

Além disso, segundo Freitas (2006), o ensino de Bioquímica no Ensino Médio é muito discreto, não sendo a disciplina ofertada diretamente, mas sim, tendo seus conceitos apresentados em tópicos de Química ou de Biologia. Dessa forma, é imprescindível uma sistemática que busque alternativas metodológicas, com o uso de programas educativos e da internet como instrumentos de ensino.

Junior (2007) avaliou a abordagem da Bioquímica nos livros didáticos de Química mais utilizados nas escolas brasileiras. 11 livros foram avaliados, e o autor concluiu que a "apresentação da Bioquímica como ciência e sua importância nos dias atuais" é insatisfatória na maioria dos livros; quase todos os livros avaliados apresentam equívocos conceituais e, apenas três experimentos foram verificados em todos os livros analisados. De acordo com o autor:

Para o estudante que adquire tais livros, a Bioquímica constitui-se em mais alguns conceitos vagos e desconexos de sua vida. Por sua vez, para o professor que utiliza tais livros, estes não trazem nada de novo e motivante para ser utilizado na aula. (Junior, 2007).

Algumas estratégias metodológicas alternativas para o ensino de Bioquímica, como o emprego de analogias, têm sido importantes para facilitar e simplificar a aprendizagem de conceitos. Como exemplo deste tipo de abordagem pode ser citado o projeto "ExpoBiochimica: Compreendendo Fenômenos Bioquímicos por Meio de Analogias", desenvolvido na Universidade Federal de São João del-Rei (UFSJ) e descrito por Barbosa e colaboradores (2012). Neste evento, foram apresentados, a partir de painéis expostos em escolas públicas, temas bioquímicos associados a sistemas analógicos cotidianos. Em um destes painéis, foi feita a comparação da síntese de proteínas com a execução de uma música, sendo a partitura equivalente ao DNA (ou seja, o código para a ação), os músicos e instrumentos atuando de forma semelhante aos agentes envolvidos na tradução (RNAs, aminoácidos e ribossomos) e a música 
correspondente a proteína, ambas sendo, portanto, um produto ou resultado desse processo. Segundo os autores, os comentários elaborados pelos alunos do Ensino Médio caracterizaram uma avaliação positiva do uso de analogias para o ensino-aprendizagem de conteúdos bioquímicos.

Além dessa estratégia, Freitas (2006) acredita que a utilização de laboratórios para a execução de aulas práticas no Ensino Médio, bem como a exploração de trabalhos científicos na forma de peças teatrais, pode favorecer o entendimento de conceitos bioquímicos.

Com o intuito de desenvolver e difundir novas ferramentas para o ensino de Ciência, principalmente no campo da Bioquímica, o CBME-USP, dentro do projeto de Educação e Difusão de Ciências, desenvolveu o modelo didático "Construindo as moléculas da vida: DNA-mRNA-Proteína" (Beltramini et al., 2006). Neste projeto, o grupo também passou a oferecer aos estudantes, professores e a comunidade de alguns municípios do estado de São Paulo, novos recursos didáticos, como mídias e jogos interativos, disponibilizados na web gratuitamente. No ano de 2011, este projeto estendeu parceria com o Departamento de Bioquímica e Biologia Molecular da UFV para também passar a ser oferecido nas escolas do ensino público da região de Viçosa, tendo o grupo PET-Bioquímica como responsável pela difusão do projeto na região.

Neste sentido, foi iniciado, em 2012, o projeto nas escolas públicas da região de Viçosa, vinculadas à SRE do município vizinho de Ponte Nova, envolvendo a capacitação de profissionais do ensino. O trabalho recebeu financiamento com aprovação de projeto pelo PET-Bioquímica em edital direcionado aos grupos PET's lançado pela Fundação de Amparo à Pesquisa do Estado de Minas Gerais (FAPEMIG). O projeto intitulado "Biologia Molecular e Biotecnologia na Formação Continuada de Professores de Ciências: Aproximando Universidade e Escola Pública" possibilitou a produção de material didático para utilização em oficinas de capacitação.

Contudo, o projeto foi estruturado na tentativa de discutir com professores do Ensino Médio formas de ensino-aprendizagem que pudessem contribuir para o aumento do interesse dos jovens diante do ensino de Ciências, levando em consideração a abordagem de temas relacionados a biotecnologia que tenham uma aplicação direta em seu cotidiano. Para isto, procurou-se a utilização de temas transversais estimuladores de discussão, experimentos práticos, uso de modelo pedagógico e o desenvolvimento de livro didático com emprego de uma linguagem que facilitasse o entendimento de aspectos bioquímicos. Buscou-se, assim, que os professores dentro de sala de aula tivessem instrumentos adicionais para estimularem a curiosidade dos estudantes de obter respostas a questões que envolvessem a ciência e tecnologia, para assim, poderem exercerem seu direito como cidadão nas decisões que envolvem aspectos científicos inerentes a sociedade moderna.

\section{Objetivos}

\section{Objetivo geral}

Capacitar professores do Ensino Médio para o uso de métodos de ensino-aprendizagem no campo da Bioquímica visando despertar maior interesse dos estudantes pela Ciência e elaborar um material complementar para o seu ensino.

\section{Objetivos específicos}

- Levantar informações sobre o ensino de Ciência realizado em escolas ligadas a SRE do município de Ponte Nova, bem como materiais didáticos usados;

- Estruturar e realizar curso para a capacitação de professores de escolas públicas no ensino de Ciência, com a utilização de temas transversais mediadores entre saberes teóricos e práticos, experimentos práticos e manipulação de modelos pedagógicos;

- Desenvolver uma metodologia e materiais didáticos adequados para o ensino da Ciência no que tange a abordagem de bioquímica;

- Oferecer capacitação aos professores da área de ciências da natureza, de forma que possam atualizar e revisar conceitos científicos, bem como suas relações e aplicações em processos e produtos biotecnológicos presentes na vida cotidiana dos estudantes;

- Propiciar a interação entre estudantes do ensino superior com professores do ensino médio de escolas públicas. 


\section{Metodologia}

\section{Levantamento de informações sobre o ensino de Ciência e parceria com as escolas públicas}

O contato com as escolas foi inicialmente mediado pela Superintendência Regional de Ensino (SRE) de Ponte Nova, MG, responsável por exercer regionalmente ações de supervisão técnica nas escolas dos municípios da região, incluindo Viçosa. Em seguida, foram agendadas as visitas dos petianos às instituições de ensino para avaliarem a estrutura das escolas, o calendário escolar, o número de professores de Biologia e Química, os conteúdos previstos nas Orientações Curriculares para o Ensino Médio do Ministério da Educação e os livros didáticos adotados para o primeiro, segundo e terceiro ano do Ensino Médio. Foi realizada uma análise crítica do material didático utilizado, assim como a verificação da existência de laboratórios de ciência nas escolas e suas estruturas físicas.

Visando divulgar o projeto e conduzir a estruturação do curso de capacitação e o desenvolvimento do material didático, alguns professores que lecionavam Química e Biologia para o último ano do Ensino Médio foram consultados, de forma a adequar o projeto ao cotidiano de trabalho do professor. Esta primeira etapa foi importante para a observação da realidade local no que tange o ensino da Ciência, tendo sido levantadas as dificuldades e potencialidades dentro de cada escola.

\section{Estruturação do curso de capacitação}

Após o estudo do material didático disponível nas escolas e com base nas sugestões feitas pelos professores, foram definidos o conteúdo teórico e a carga horária do curso de capacitação. Um novo contato com a SRE foi realizado para agendamento das oficinas. A Superintendência apoiou o projeto com liberação de professores de 20 escolas da região para a participação no curso.

Temas teóricos de Bioquímica que faziam parte do plano pedagógico e do livro didático, empregados no Ensino Médio, foram sistematizados e relacionados com assuntos do cotidiano, de forma que aproximasse o conhecimento científico da área a tecnologias e produtos que fazem parte da rotina do estudante.

Os professores liberados pela SRE foram divididos em duas turmas para participarem das oficinas de capacitação realizadas em agosto de 2012 e novembro de 2013, os encontros aconteceram no campus da Universidade Federal de Viçosa, sendo que cada um deles foi ministrado em dois dias, compreendendo 15 horas de carga horária presencial.

No primeiro módulo foi levantado e discutido o tema "plantas transgênicas". Uma pesquisadora da UFV, com destacada atuação nesta área, foi convidada para dar uma palestra sobre as bases científicas e tecnológicas no que diz respeito a transgênicos. Após a apresentação foi aberto um espaço para discussão, possibilitando que os professores do Ensino Médio colocassem suas opiniões e tirassem dúvidas sobre o assunto. A escolha deste tema justificou-se pela figuração constante do mesmo na mídia, sendo assim parte do cotidiano dos alunos. Posteriormente, este tema transversal serviu de subsídio para a inserção de conceitos teóricos de Bioquímica, tais como estrutura de ácidos nucleicos e de proteínas.

Durante as oficinas também foram realizadas dinâmicas em grupo para estimular o emprego de novos recursos didáticos no processo de ensino-aprendizagem de Bioquímica. Para tornar o ensino mais atrativo e compreensível ao se abordar disposição tridimensional de ácidos nucleicos e de proteínas foi empregado o modelo "DNA-RNAm-Proteína: Construindo as moléculas da vida" (Figura 1) e um CD contendo aulas narradas por pesquisadores, ambos desenvolvidos no Instituto de Física de São Carlos (IFSC) da Universidade de São Paulo (Beltramini, 2006). Além disso, foram realizados experimentos práticos de extração de DNA a partir de frutas e uma apostila foi desenvolvida pelo grupo PET.

Após o treinamento dos professores para o uso do modelo “DNA-RNAm-Proteína: Construindo as moléculas da vida", foram distribuídos kits contendo conjunto de peças preparadas para uso dentro da sala de aula para cada escola participante, de forma que os professores propagassem este recurso nas aulas de Biologia e Química que envolvessem tópicos de Bioquímica. A compra e distribuição gratuita dos kits didáticos a todas as escolas participantes desse projeto foram viabilizados com recursos oriundos do Instituto Nacional de Ciências e Tecnologia em Biotecnologia Estrutural e Química Medicinal em Doenças Infecciosas, em parceria formalizada com a professora Leila Maria Beltramini do Centro 
de Biotecnologia Molecular Estrutural do Instituto de Física da USP de São Carlos. A equipe de popularização da ciência, coordenada pela professora Beltramini, também foi responsável pela capacitação inicial dos petianos para o uso dos modelos didáticos, realizada por meio de oficinas presenciais na USP de São Carlos, SP.

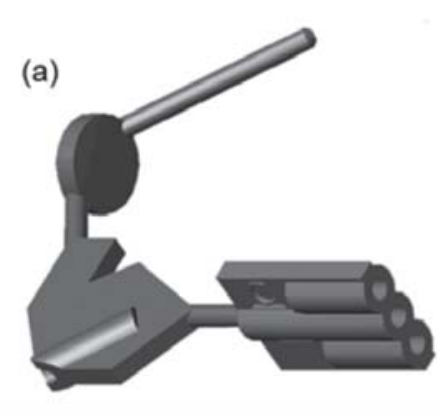

(c)

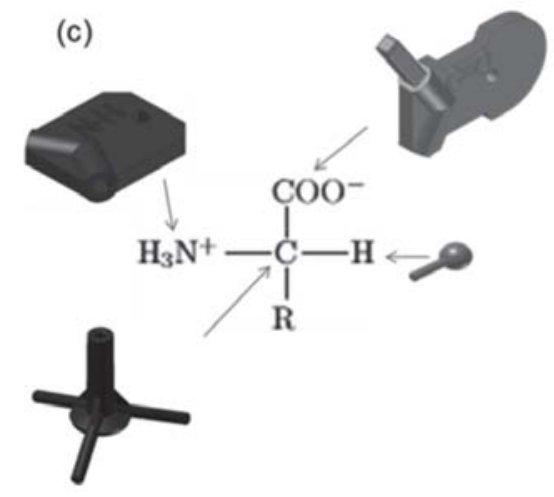

(b)

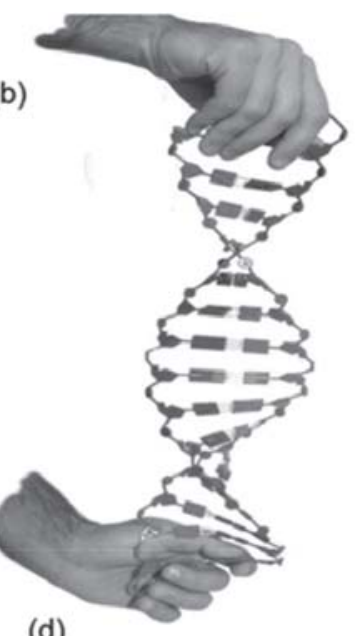

(d)

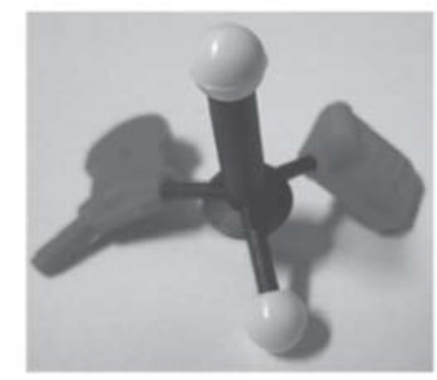

Figura 1 - Componentes plásticos do modelo “DNA-RNAm-Proteína: Construindo as moléculas da vida". (a) grupo fosfato conectado à pentose e à base nitrogenada; (b) estrutura da dupla hélice da molécula de DNA; (c) grupamentos necessários para a construção de um aminoácido; (d) estrutura do aminoácido glicina.

Fonte: Beltramini, L. M.; Silva, A. R.; Costa, G. Roteiros Práticos do Instituto de Física da USP de São Carlos

\section{Desenvolvimento de livro didático}

Durante a experiência nas oficinas do projeto com os professores do Ensino Médio surgiu a proposta da produção do livro "Bioquímica nas Escolas: Uma Abordagem Lúdica para o Ensino Médio". A confecção desse livro texto voltado para o ensino de Bioquímica teve como objetivo relacionar a explicação do conteúdo teórico ao emprego do modelo didático recebido pelos professores. Esta proposta surgiu após a detecção de uma necessidade demonstrada pelos professores durante as oficinas e também na leitura prévia dos livros de Biologia e Química adotados pelas escolas.

A produção do livro ficou sob a responsabilidade dos petianos do curso Bacharelado em Bioquímica da UFV.

\section{Avaliação}

A fim de avaliar a relevância do projeto desenvolvido e sua perspectiva de aplicabilidade dentro da sala de aula, foi distribuído ao final do curso de capacitação um questionário aos professores que participaram das atividades.

As perguntas feitas abrangeram aspectos relacionados ao conteúdo abordado no curso, a viabilidade de aplicação dos recursos didáticos discutidos na oficina em sala de aula, possibilidade de repetição dos experimentos práticos apresentados e opinião quanto ao emprego do kit no processo de ensino-aprendizagem de Química e Biologia. 


\section{Resultados e Discussão}

\section{Oficinas de métodos educacionais em bioquímica}

O projeto iniciou-se com a oficialização do planejamento do curso de capacitação oferecido pelo PETBioquímica com a SRE de modo que a carga horária do treinamento pudesse ser contabilizada, como previsto pela Secretaria de Educação e Estado, e ao final do curso os professores pudessem ser liberados de suas atividades. Durante a reunião de planejamento com analistas da SRE e professores do Ensino Médio, levantou-se o número de escolas da região que oferecem essa etapa do ensino básico, além do número e nomes de professores de Química e Biologia dessas escolas e seus contatos. Também foi importante garantir que os professores participantes do treinamento fossem liberados de suas atividades dentro da escola, visto que as oficinas ocorreram em dias letivos. $O$ transporte para aqueles professores que não residiam na cidade de Viçosa foi viabilizado, ficando este investimento sob a responsabilidade da SRE.

Durante a etapa de planejamento foi relatada pelos professores a importância da interação com a universidade para a aquisição de novos conhecimentos no campo da Bioquímica e da Biologia Molecular que aparecem como conteúdo didático em vários momentos do Ensino Médio, sobretudo em decorrência do aprendizado nas disciplinas de ciências da natureza, como de Biologia e Química, e das tecnologias a elas relacionadas. De acordo com a Lei de Diretrizes e Bases da Educação Nacional (LDB/96), quanto ao caráter do Ensino Médio, faz-se necessário que o aprendizado de suas disciplinas se manifeste de forma interdisciplinar e contextualizada, visando o desenvolvimento de competências humanas relacionadas a aspectos científico-tecnológicos.

De acordo com a LDB/96, do Ensino Médio, que é considerada como última e complementar etapa do Ensino Básico, espera-se o aprofundamento e a articulação interdisciplinar dos saberes entre disciplinas das ciências da natureza. Assim, o envolvimento de conteúdos teóricos e práticos que abranjam tecnologias que os próprios estudantes utilizam em seu dia a dia, favorece o desenvolvimento de uma consciência mais crítica de seus deveres e direitos como cidadãos, dando-lhes subsídio para uma participação mais efetiva na sociedade contemporânea. As atuais tecnologias envolvendo o conhecimento de Bioquímica, como geração de energia, novos fármacos, transgênicos, alimentos e outros, são atualmente temas de grande vivência dos alunos e educadores, principalmente pelo fato de estarem constantemente veiculados pelos meios de comunicação. O fato dos estudantes já serem sensibilizados por situações problematizadoras, decorrentes da aplicação tecnológica da biotecnologia relacionada a questões ambientais, de saúde e econômica, locais e globais, torna esta temática mais familiar e de maior interesse para a compreensão da realidade.

Foram treinados 34 professores, provenientes de 20 escolas, abrangendo 12 municípios da região. As oficinas de capacitação foram oferecidas em duas edições, sendo que cada professor participou de uma única oficina que compreendeu em dois módulos, totalizando 15 horas presenciais. A capacitação foi ministrada por graduandos do curso de Bacharelado em Bioquímica, todos do grupo PET Bioquímica, além de professores pesquisadores que foram convidados a apresentar suas linhas de pesquisa em áreas relacionadas à Bioquímica.

O treinamento teve carga horária total de 20 horas distribuídas em dois módulos presenciais totalizando 15 horas e um módulo não presencial de 05 horas no qual foram utilizados jogos virtuais e multimídia. O primeiro módulo, com duração de 08 horas, foi dedicado à palestra de um pesquisador mostrando uma aplicação atual do conteúdo e à apresentação de uma atividade prática que poderia ser facilmente realizada em sala de aula sem a necessidade de um laboratório de ensino. O segundo módulo, composto de 07 horas, foi destinado ao embasamento teórico do tema e à elucidação do manuseio dos kits (Quadro 1).

Assim, a programação contou com a apresentação de palestras com renomados pesquisadores da área de biotecnologia, de forma a contextualizar os conhecimentos. Temas como transgênicos, bioquímica forense e descoberta de novos fármacos foram abordados nas palestras e serviram como contexto para explicação dos fenômenos bioquímicos como bioquímica celular, tradução, síntese de proteínas entre outros.

Após as palestras iniciais e a discussão entre os professores sobre os temas apresentados, a oficina teve continuidade com a realização de experimento prático, como extração de DNA de frutas e explicação de fundamentos de Bioquímica com o emprego do kit didático com modelos de ácidos nucleicos e de aminoácidos. Em relação ao kit, Oliveira e colaboradores (2007) destacaram seu fácil manuseio como uma razão do interesse e curiosidade dos alunos. Outros benefícios do kit também 
foram destacados nesse trabalho, como a oportunidade de visualização como facilitadora da compreensão e percepção da estrutura molecular e a possibilidade de simulação de processos como duplicação e transcrição.

Embora Bioquímica e Biotecnologia sejam temas abordados separadamente em livros didáticos de Química e Biologia, o assunto exige conhecimento de ambas as ciências para uma melhor compreensão por parte dos estudantes. A participação de professores de ambas as disciplinas, tornou possível um enfoque interdisciplinar sobre os temas abordados. Além disso, os professores foram encorajados a desenvolver atividades relacionadas ao projeto de forma conjunta. Além de enriquecer o trabalho em sala de aula, extrapolando metodologias triviais e facilitando a assimilação do conteúdo, as propostas e materiais fornecidos nas oficinas permitem o trabalho interdisciplinar aumentando o interesse de alunos inclusive não muito participativos nas aulas regulares. Sugere-se uma maior segurança dos professores para testar novas metodologias em situações nas quais podem contar com o suporte de colaboradores, sejam eles do seu ambiente de trabalho ou não. Há ainda uma possibilidade de elevação da autoestima dos professores, por meio dessa capacitação, que ao se sentir hábeis, estão mais aptos a criar novas formas de trabalho, inclusive de forma interdisciplinar (Oliveira et al., 2007).

Para a prática de extração de DNA buscou-se utilizar materiais simples, de fácil aquisição pelas escolas e possível de ser realizado dentro de sala de aula, possibilitando que mesmo as escolas sem laboratórios de ciência pudessem realizá-la. Durante a prática de extração de DNA de frutas, assuntos como constituição da célula vegetal puderam ser explorados biologicamente, enquanto constituição química das células e interação desses compostos com solvente orgânicos, quimicamente, construindo assim o enfoque interdisciplinar.

O emprego do modelo "Construindo as moléculas da vida: DNA-mRNA-Proteína" para explicar a estrutura química e a função da proteína, foi importante para a sua visualização tridimensional que muitas vezes fica prejudicada quando se estuda em livros (Figura 2).

Quadro 1 - Conteúdos abordados na primeira oficina presencial da capacitação

\begin{tabular}{clc}
\hline Módulo & \multicolumn{1}{c}{ Conteúdo } & Duração \\
\hline I & Apresentação do curso e mesa de abertura & 08 horas \\
& Palestra “Pesquisas com transgênicos na UFV” & \\
& Experimento prático de extração de DNA & \\
& Organização do genoma na Célula: estruturando DNA e RNA \\
& Montagem dos modelos tridimensionais de DNA \\
& Replicação e transcrição & 07 horas \\
& Enzimas de Restrição & \\
& Tradução & \\
& Estrutura de aminoácidos e ligação peptídica & \\
II & Eontagem dos modelos tridimensionais de proteínas \\
& Ensino sobre estrutura tridimensional de proteínas com uso de modelo didático & \\
\end{tabular}

Fonte: Elaborado pelos autores.
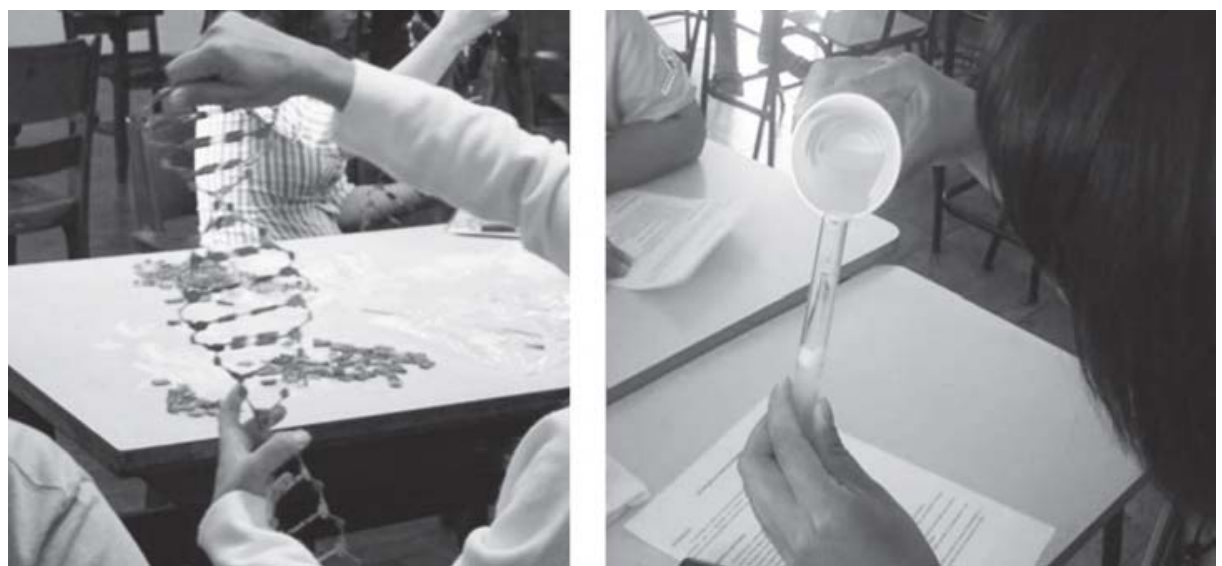

Figura 2 - Imagens das oficinas com professores usando o modelo didático (esquerda) e extraindo DNA de banana (direita).

Fonte: Elaborado pelos autores. 
Durante as oficinas, o uso de exemplos que aproximassem a Bioquímica do dia a dia dos estudantes foi importante para sensibilizar os professores do Ensino Médio para a contextualização do conhecimento científico-tecnológico. No campo da Biologia, o aprendizado disciplinar em temas que estejam inseridos dentro dos conteúdos de Bioquímica podem ser relacionados a várias abordagens relevantes para a biosfera, saúde humana e economia global, interagindo com outras áreas, como das ciências humanas, assumindo um enfoque interdisciplinar. Oliveira e colaboradores (2007) destacam a importância da contextualização dos temas abordados de acordo com o cotidiano dos alunos. Essa aproximação da aula com o dia a dia dos estudantes pode ser exemplificada pelo relato apresentado pelos autores em relação a oficinas de formato semelhante a essas apresentadas neste trabalho realizadas em São Paulo, com retorno positivo dos alunos. Três professores que participaram da oficina propuseram uma situação-problema real, a conhecida troca de bebês no hospital de Sertãozinho-SP, ocorrida nos anos 1980, para abordar o tema das oficinas em sala de aula. Além disso, recortes de jornais foram usados para discussão da relevância de testes de paternidade em atividades em grupo.

Essa interação entre o conteúdo teórico de Bioquímica e da Biologia Molecular, pode levar para a sala de aula importantes debates sobre tecnologias que estão atualmente disponíveis na sociedade, como de manipulação do DNA e clonagem, o que traz à tona aspectos éticos envolvidos na produção e aplicação do conhecimento científico e tecnológico, trazendo uma reflexão sobre as relações entre a ciência, a tecnologia e a sociedade (Berger Filho et al., 2016). Esta educação reforça a participação cidadã do estudante na condução social local e global, trazendo elementos teóricos para subsidiar seu posicionamento e atuação no mundo contemporâneo.

Ao final da capacitação, o Kit "Construindo as moléculas da vida: DNA-mRNA-Proteína", contendo vários pacotes com os modelos didáticos foi distribuído a cada escola que teve pelo menos um professor capacitado, de forma a propiciar a oportunidade de usar o método de ensino e aprendizagem trabalhado no curso no ambiente escolar.

\section{Avaliação das oficinas}

O projeto visou à capacitação dos professores do Ensino Médio de modo que os conteúdos abordados durante o treinamento pudessem ser ministrados aos seus alunos utilizando os materiais fornecidos. Ao final da capacitação alguns aspectos foram avaliados pelos professores participantes, de forma a verificar principalmente a exequibilidade do método trabalhado.

Quanto à escolha dos temas transversais abordados durante as oficinas, a maioria opinou que se tratavam de temas atuais e de interesse para os professores. Após a palestra sobre "Transgênicos", várias dúvidas relacionadas a questões científicas, sociais e econômicas puderam ser sanadas pelos professores. O outro tema abordado em palestra, "Bioquímica Forense" também despertou grande interesse, uma vez que a mesma foi relacionada a fundamentos e aplicações de técnicas usadas para desvendar atos criminosos na sociedade.

Entre as escolas participantes das oficinas, 64\% delas apresentavam laboratórios de ciência no momento da pesquisa. No entanto, grande parte dos professores consultados alegou que, em geral, os laboratórios são "poucos equipados" ou "não estão em condições de uso". É consenso entre os educadores que são nas aulas práticas de ciências que os alunos vivenciam os conteúdos abordados nas aulas teóricas, facilitando assim o aprendizado. Esta falta de infraestrutura para laboratórios de ciência nas escolas consiste em um grande obstáculo para a formação de um aluno interessado na carreira científica, bem como para o entendimento de fenômenos descritos nos livros didáticos (Berezuk, Inada, 2010).

Para 91\% dos professores pesquisados, a prática de extração de DNA realizada durante o curso é factível de ser implementada nas escolas. Esta aceitação pode ser justificada pela simplicidade e pelo baixo custo dos materiais usados, por fazer parte do conteúdo abordado no currículo, bem como pela sua contextualização com tecnologias e produtos atualmente usados na sociedade. A totalidade dos entrevistados aprovou o uso do modelo didático "DNA-RNAm-Proteína: Construindo as moléculas da vida" no ensino de Bioquímica e Biologia Molecular, afirmando ser uma forma inovadora de ensino sobre o tema e que facilita a aproximação da teoria com a realidade.

Os educadores se mostraram otimistas quanto à abordagem do assunto bioquímica e biotecnologia na forma dos modelos moleculares. Alguns deles acrescentaram ainda que é preciso inovar a metodologia em sala de aula e, que a apresentação de aulas seguindo essa proposta favorece a compreensão dos alunos, uma vez que o conteúdo é apresentado de forma mais esclarecedora. Nesse 
sentido, observa-se que o curso de formação continuada oferecido apresenta-se não apenas como uma oportunidade de atualização dos conhecimentos, dado as diversas inovações que surgem no campo da biotecnologia, mas, também, como uma forma de minimizar as dificuldades pertinentes ao processo ensinoaprendizagem vivenciadas pelos professores no dia a dia da sala de aula (Urzetta e Cunha, 2013).

\section{Desenvolvimento de material didático}

A fim de tornar as oficinas de capacitação mais personalizadas e objetivas, o grupo PET Bioquímica desenvolveu uma cartilha com o conteúdo abordado e protocolos de aulas práticas que pudessem ser facilmente realizadas sem a necessidade de laboratórios sofisticados. A cartilha foi distribuída aos professores que participaram das oficinas de capacitação.

Além da apostila, o grupo desenvolveu um livro intitulado "Bioquímica nas Escolas: uma abordagem lúdica para o ensino médio" (Figura 3). O ideal da escrita do livro surgiu após a análise dos livros didáticos utilizados pelos professores e a constatação de que os assuntos relacionados à Bioquímica e Biologia Molecular no Ensino Médio muitas vezes não são abordados de forma contextualizada e interdisciplinar. Além disso, um estudo realizado por Xavier e colaboradores (2006) constatou que os livros didáticos para o Ensino Médio não estão atualizados no estudo dos temas considerados essenciais para perfeito entendimento e aquisição de informações associadas ao rápido avanço do conhecimento na área da biologia moderna. Dessa forma, buscou-se a produção de um material de leitura que pudesse ser utilizado por professores de Biologia e Química de forma a trabalhar os conteúdos de forma conjunta, empregando uma abordagem lúdica e interessante para o aluno.

O livro conta com dezessete (17) capítulos totalmente escritos pelos alunos integrantes do grupo PET, sendo que o capítulo dezessete (17), o último capítulo do livro, trata do uso do kit "Construindo as moléculas da vida: DNA-mRNA-proteína" como metodologia de ensino, e apresenta um manual de instruções de como proceder com as peças e sugestões de atividades para oficinas em salas de aula. O livro é constituído de três partes, sendo a primeira referente a "Fundamentos de Bioquímica", apresentando revisões sobre teoria celular, estruturas celulares e transporte, e algumas sumarizações sobre bioenergética, físico-química e química orgânica; a segunda parte, "Bioquímica de Macromoléculas" expõe conceitos sobre macromoléculas abundantes na célula e água, solvente universal e reagente nas reações de hidrólise; e a terceira trata de "Biologia Molecular", sendo que um capítulo é dedicado exclusivamente às oficinas de capacitação, que abordam a estrutura do DNA, RNA e proteínas e os processos de replicação, transcrição e tradução.

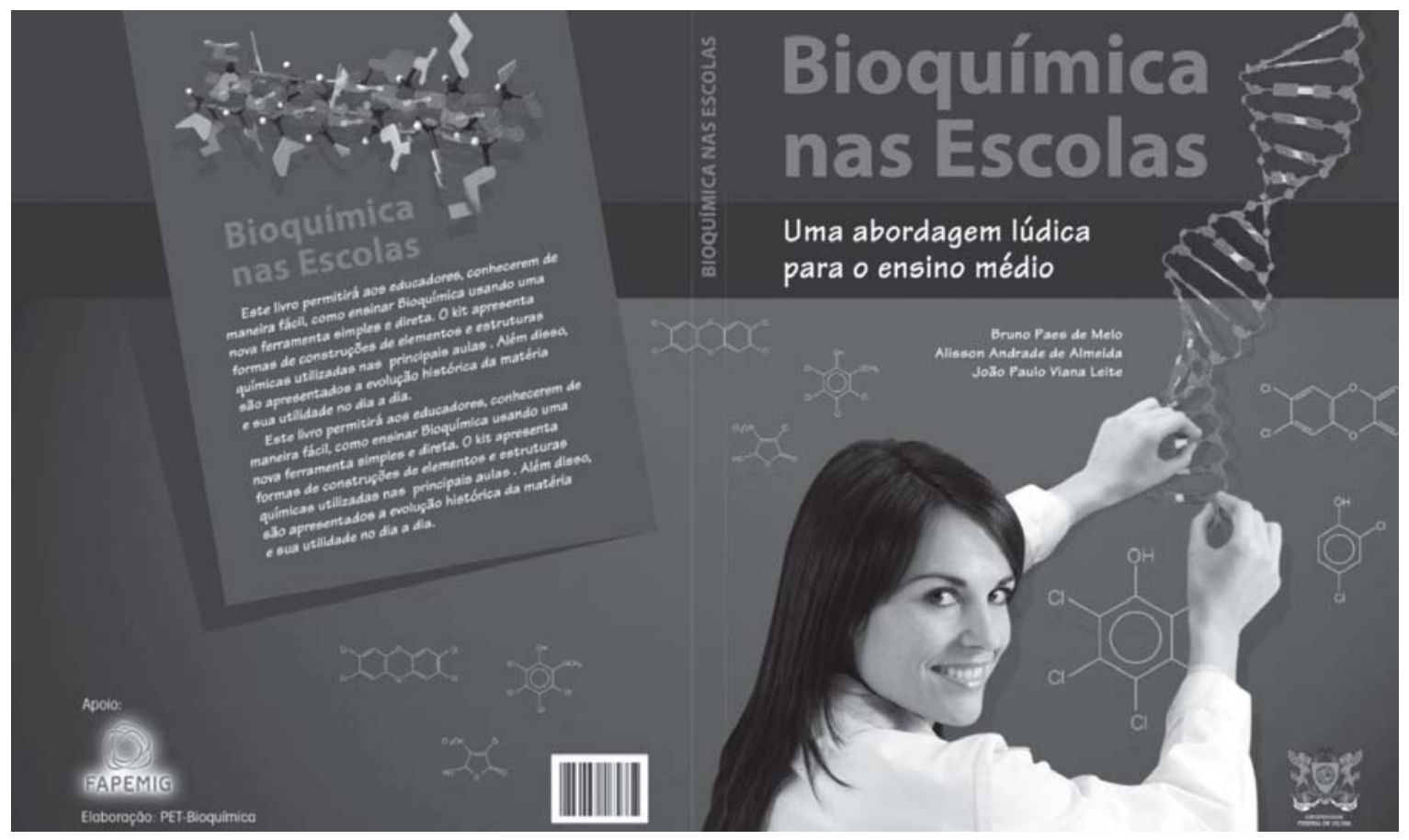

Figura 3 - Capa do livro Bioquímica nas Escolas: uma abordagem lúdica para o ensino médio.

Fonte: Elaborado pelos autores. 
O material foi desenvolvido com o objetivo de distribuição gratuita para as escolas participantes do projeto "Biologia Molecular e Biotecnologia na Formação Continuada de Professores de Ciências: Aproximando Universidade e Escola Pública". Foi providenciado o registro da obra junto a Biblioteca Nacional para obtenção do ISBN (Número Padrão Internacional de Livro), sendo a este conferido o número 978-85-911249-1-6.

\section{Conclusões}

O processo de ensino-aprendizagem de ciência durante o ensino médio é de grande importância para a formação crítica dos alunos, de forma que alimente o interesse pelas questões científicas e tecnológicas tão presentes na nossa sociedade moderna. Para isto, a atualização permanente dos professores e o oferecimento de métodos pedagógicos e materiais didáticos apropriados consistem em grande desafio para a melhoria de qualidade do ensino.

O presente projeto visou pela indissociabilidade entre ensino, pesquisa e extensão possibilitando que os graduandos petianos tivessem uma maior interação com a realidade de escolas públicas no que tange o ensino de ciências da natureza. Pode-se verificar que a aproximação entre a universidade e as escolas do ensino básico pode resultar em uma importante troca de saberes e também em um instrumento para a reciclagem dos professores e de formação para o futuro educador.

Conclui-se que a abordagem de ensino de Bioquímica utilizada durante a oficina, bem como o emprego do material didático desenvolvido, podem servir como instrumento para aumentar o interesse dos estudantes pelo ensino de ciência nas escolas e fomentar a formação de novos pesquisadores científicos.

\section{Fontes de financiamento}

Secretaria de Ensino Superior do Ministério da Educação e Cultura (SESu-MEC) e Fundação de Amparo a Pesquisa do Estado de Minas Gerais (FAPEMIG).

\section{Agradecimentos}

À Secretaria de Ensino Superior do Ministério da Educação e Cultura (SESu/MEC), por intermédio do Programa de Educação Tutorial pelo financiamento das bolsas dos petianos. À FAPEMIG pelo apoio financeiro no desenvolvimento deste projeto. Ao Instituto Nacional de Biotecnologia Estrutural e Química Medicinal em Doenças Infecciosas, que disponibilizou recurso para a compra e distribuição gratuita dos kits didáticos doados a todas as escolas participantes desse projeto. À professora Leila Beltramini e sua equipe do Instituto de Física da USP-São Carlos pela importante colaboração e capacitação dos petianos. Aos profissionais da Secretaria Regional de Ensino de Ponte Nova pelo auxílio no contato com as escolas e professores. E, principalmente, aos educadores das Escolas Públicas que apostaram no projeto, se dedicaram durante a capacitação e que continuam buscando semear nos alunos o interesse pela Ciência.

\section{Referências Bibliográficas}

BARBOSA, J. U., Leal, M. C., Rossi, S. Q., Dias, T. N., Ferreira, K. A., \& Oliveira, C. P. De. Analogias para o ensino de bioquímica no nível médio. Ensaio - Pesquisa Em Educação Em Ciências, 14(1), 195208, 2012.

BELTRAMINI, L.M.; Araújo, A.P.; de Oliveira, T.H.; dos Santos, A.L.D.; da Silva, A.R.; dos Santos, N.F. A new three-dimensional educational model kit for building DNA and RNA molecules: Development and evaluation. Biochem. Mol. Biol. Educ., v.34, n.3, p.187-93, 2006.

BEREZUK, P.A.; Inada, P. Avaliação dos laboratórios de ciências e biologia das escolas públicas e particulares de Maringá, Estado do Paraná. Acta Scientiarum. Human and Social Sciences, v. 32, n. 2, p. 207-215, 2010.

BERGER, F., R.L.; Pereira, A.R.S.; Maia, E. M. Parâmetros curriculares nacionais - Ensino Médio. Parte III - Ciências da Natureza, Matemática e suas Tecnologias. MEC, [s.d.]. Disponível em: <http:// portal.mec.gov.br/seb/arquivos/pdf/ciencian.pdf>. Acesso em: 20 maio 2016. 
BOSSOLAN, N.R.S.; Santos, N.F.; Moreno, R.R.; Beltramini, L.M. O centro de biotecnologia molecular estrutural: aplicação de recursos didáticos desenvolvidos junto ao ensino médio. Cienc. Cult., v.57, n.4, p. 41-42. 2005.

DE OLIVEIRA, M.R.G., de Oliveira T. H. G., Bossolan N.R.S., Beltramini L.M.: O impacto de um curso em biologia molecular e biotecnologia na formação continuada de professores de ciências: aproximando universidade e escola pública. VI ENPEC-Encontro Nacional de Pesquisa em educação em ciências, 2007.

FOUREZ, G. Crise no ensino de ciências? Investigações em ensino de ciências, v. 8, n. 2, p. 109-123, 2003.

FREITAS, A. L. P. Bioquímica: do cotidiano para as salas de aula - Entrevista. CBME Informação, 2006, São Carlos-SP. Disponível em: < http:/ / cbme.usp.br/files/edicao_pdf/edicao11.pdf>. Acesso em: 25 out. 2016.

GERMANO, M.G. Uma nova ciência para um novo senso comum. Campina Grande: Eduepb, 2011.

GERMANO, M.G.; Kulesza, W. A. Popularização da ciência: uma revisão conceitual. Caderno Brasileiro de Ensino de Física, v.24, n.1, 2007.

GOUW, A.M.S.; Mota, H.S.; Bizzo, N. O currículo de Ciências e o interesse dos estudantes brasileiros: uma aproximação necessária. Cadernosc Enpec, v.3, n.2, p.7-34, 2013.

JÚNIOR, W. E. F. Bioquímica no ensino médio?! (de)limitações a partir da análise de al-guns livros didáticos de química. Ciência e Ensino, v.1, n.2, 2007.

LOGUERCIO, R. Mapeando a educação em bioquímica no Brasil. Ciências e cognição, 10 (51), 147-155, 2007.

MACHADO, S. M. de, Ricardo, J., Sugai, J. K., Santos, M., Bonorino, R., \& Antônio, R. V. Bioquímica através da animação. Revista Eletrônica de Extensão, UFSC. Santa Catarina, 1, 1-10, 2004.

MINISTÉRIO DA EDUCAÇÃO, Secretaria de Educação Básica. Orientações curriculares para o ensino médio. v.2, p. p.15-134, 2006.

MLODINOW, L. De primatas a astronautas: a jornada do homem em busca do conhecimento. Rio de Janeiro: Zahar, 2015.

SANTOS, B. S. Crítica da razão indolente: contra o desperdício da experiência. São Paulo: Cortez, 2005.

URZETTA, F.C., Cunha, A.M.O. Análise de uma proposta colaborativa de formação continuada de professores de ciências na perspectiva do desenvolvimento profissional docente. Ciênc. Educ., v. 19, n. 4, p. 841-858, 2013.

VÁZQUEZ, A.A.; Manassero, M.A.M. El declive de las actitudes hacia la ciencia de los estudiantes: un indicador inquietante para la educación científica. Rev. Eureka Enseñ. Divul. Cien., v. 5, n. 3, p. 274-292, 2008.

XAVIER, M.C.F., Freire, S.A., Moraes, M.O. A nova (moderna) biologia e a genética nos livros didáticos de biologia no ensino médio. Ciência E Educação, v. 12, n. 3, p. 275-289, 2006.

Recebido para publicação em 31/5/2016 e aprovado em 17/10/2016. 